\title{
Antitumour activity of trabectedin in myelodysplastic/myeloproliferative neoplasms
}

Michela Romano ${ }^{1}$, Matteo Giovanni Della Porta ${ }^{2,3}$, Anna Galli ${ }^{2}$, Nicolò Panini ${ }^{1}$, Simonetta Andrea Licandro ${ }^{1}$, Ezia Bello ${ }^{1}$, llaria Craparotta ${ }^{1}$, Vittorio Rosti ${ }^{4}$, Elisa Bonetti ${ }^{4}$, Richard Tancredi ${ }^{5}$, Marianna Rossi ${ }^{2}$, Laura Mannarino ${ }^{1}$, Sergio Marchini ${ }^{1}$, Luca Porcu ${ }^{1}$, Carlos M Galmarini ${ }^{6}$, Alberto Zambelli ${ }^{7}$, Marco Zecca ${ }^{8}$, Franco Locatelli, ${ }^{9,10}$, Mario Cazzola ${ }^{2,11}$, Andrea Biondi ${ }^{12}$, Alessandro Rambaldi ${ }^{13}$, Paola Allavena ${ }^{14}$, Eugenio Erba ${ }^{1}$ and Maurizio D'Incalci ${ }^{*, 1}$

${ }^{1}$ Department of Oncology, IRCCS Istituto di Ricerche Farmacologiche Mario Negri, Via La Masa 19, Milan, Italy; ${ }^{2}$ Department of Hematology/Oncology, Fondazione IRCCS Policlinico San Matteo, Pavia, Italy; ${ }^{3}$ Department of Internal Medicine, University of Pavia, Pavia, Italy; ${ }^{4}$ IRCCS Policlinico S. Matteo Foundation, Center for the Study of Myelofibrosis, Pavia, Italy; ${ }^{5}$ Division of Clinical Oncology, IRCCS Fondazione S. Maugeri, Pavia, Italy; ${ }^{6}$ Oncology Unit, PharmaMar SAU Colmenar Viejo, Madrid, Spain; ${ }^{7}$ Medical Oncology Unit, Hospital Papa Giovanni XXIII, Bergamo, Italy; ${ }^{8}$ Department of Pediatric Hematology-Oncology, Fondazione IRCCS Policlinico San Matteo, Pavia, Italy; ${ }^{9}$ Department of Pediatric Hematology-Oncology, IRCCS, Bambino Gesù Children's Hospital, Roma, Italy; ${ }^{10}$ Department of Pediatric Science, University of Pavia, Pavia, Italy; ${ }^{11}$ Department of Molecular Medicine, University of Pavia, Pavia, Italy; ${ }^{12}$ Clinica Pediatrica, Università di Milano, Ospedale San Gerardo, Monza, Italy; ${ }^{13}$ Hematology and Bone Marrow Transplantation Unit, Hospital Papa Giovanni XXIII, Bergamo, Italy and ${ }^{14}$ IRCCS Clinical and Research Institute Humanitas, Rozzano, Milano, Italy

Background: Juvenile myelomonocytic leukaemia (JMML) and chronic myelomonocytic leukaemia (CMML) are myelodysplastic myeloproliferative (MDS/MPN) neoplasms with unfavourable prognosis and without effective chemotherapy treatment. Trabectedin is a DNA minor groove binder acting as a modulator of transcription and interfering with DNA repair mechanisms; it causes selective depletion of cells of the myelomonocytic lineage. We hypothesised that trabectedin might have an antitumour effect on MDS/MPN.

Methods: Malignant CD14 + monocytes and CD34 + haematopoietic progenitor cells were isolated from peripheral blood/bone marrow mononuclear cells. The inhibition of CFU-GM colonies and the apoptotic effect on CD14+ and CD34 + induced by trabectedin were evaluated. Trabectedin's effects were also investigated in vitro on THP-1, and in vitro and in vivo on MV-4-11 cell lines.

Results: On CMML/JMML cells, obtained from 20 patients with CMML and 13 patients with JMML, trabectedin - at concentration pharmacologically reasonable, 1-5 nM - strongly induced apoptosis and inhibition of growth of haematopoietic progenitors (CFUGM). In these leukaemic cells, trabectedin downregulated the expression of genes belonging to the Rho GTPases pathway (RAS superfamily) having a critical role in cell growth and cytoskeletal dynamics. Its selective activity on myelomonocytic malignant cells was confirmed also on in vitro THP-1 cell line and on in vitro and in vivo MV-4-11 cell line models.

Conclusions: Trabectedin could be good candidate for clinical studies in JMML/CMML patients.

*Correspondence: Dr M D'Incalci; E-mail: maurizio.dincalci@marionegri.it

Received 27 September 2016; revised 28 November 2016; accepted 29 November 2016; published online 10 January 2017

(c) 2017 Cancer Research UK. All rights reserved 0007-0920/17 
Juvenile myelomonocytic leukaemia (JMML) and chronic myelomonocytic leukaemia (CMML) are rare myelodysplastic/myeloproliferative neoplasms (MDS/MPN), respectively, affecting children, usually under the age of 4 years, and elderly people (Vardiman et al, 2009). CMML and JMML share similar clinical (splenomegaly due to infiltration of malignant cells and high risk of leukaemic evolution), laboratory (monocytosis, anaemia and thrombocytopenia) and histological (marrow myelomonocytic hyperplasia) features (Emanuel, 2008; Loh, 2010; Patnaik et al, 2014). Despite the overlapping clinical phenotype, the molecular architecture of JMML and CMML appears to be clearly distinct. In JMML, the neoplastic myelomonocytic clone is hypersensitive to GM-CSF and mutually exclusive abnormalities in the GM-CSF signalling pathway (i.e., inactivation of the NF1 tumour suppressor gene or oncogenic mutations in NRAS, KRAS2, PTPN11 or CBL) have been seen in the majority of patients (Loh, 2011; Stieglitz et al, 2015). In CMML, recurrent somatic mutations are described in genes encoding for a component of the RNA splicing machinery (SRSF2), signalling molecules (NRAS, KRAS and CBL), epigenetic regulators (TET2, IDH1/2 and ASXL1) and transcription factors (RUNX1) (Cazzola et al, 2013; Itzykson and Solary, 2013; Itzykson et al, 2013).

Allogeneic stem cell transplantation is still the only curative treatment for MDS/MPN neoplasms (Locatelli et al, 2005; Locatelli and Niemeyer, 2015; Symeonidis et al, 2015). However, the disease relapses in a significant proportion $(30-50 \%)$ of JMML patients and only $<10 \%$ of those with CMML are eligible on account of older age or comorbidities (Locatelli et al, 2005; Locatelli and Niemeyer, 2015; Symeonidis et al, 2015). So far, neither intensive nor low-dose chemotherapy has consistently improved the outcome of these patients (Patnaik et al, 2014; Locatelli and Niemeyer, 2015). For these reasons, there is clearly a need to identify new, effective treatment strategies for JMML and CMML.

Trabectedin (Yondelis) is a marine natural compound isolated from the Caribbean tunicate Ecteinascidia turbinata in 1990 (Zewail-Foote and Hurley, 1999).

It is approved in Europe and in many countries worldwide as a second-line therapy for the treatment of adult patients with advanced soft tissue sarcoma (Yovine et al, 2004; Grosso et al, 2007; Demetri et al, 2009, 2016), relapsed ovarian cancers (Monk et al, 2010) and is currently under clinical evaluation in many other malignancies. Its antitumour effects are due to multiple mechanisms (D'Incalci and Galmarini, 2010). This drug binds the minor groove of DNA, thus interacting with different DNA repair mechanisms (Damia et al, 2001; Erba et al, 2001; Soares et al, 2005; Tavecchio et al, 2008), it can also act as a transcription modulator (Minuzzo et al, 2000; Friedman et al, 2002; Di Giandomenico et al, 2014). In mouse tumour models, trabectedin causes selective depletion of monocytes in the blood, spleen and tumour, by activating caspase-8-dependent apoptosis and increasing the expression of TRAIL receptors (Germano et al, 2013). Tumourassociated macrophages (TAMs) promote disease progression by supporting cancer cell survival, proliferation and invasion (DeNardo et al, 2009; Steidl et al, 2010; Allavena and Mantovani, 2012). In cancer patients who receive trabectedin-based therapies, selective monocyte depletion also has been reported (Allavena et al, 2005; D’Incalci and Galmarini, 2010; Germano et al, 2010).

These observations suggest that trabectedin exerts its distinct effects on monocytes/macrophages and it may affect the tumour microenvironment by acting on TAMs that promote disease progression through support to cancer cell survival, proliferation and invasion.

These findings provide strong proof-of-concept evidence for monocyte/macrophage targeting in humans and suggest interesting prospects for the rational exploitation of the particular properties of trabectedin in patients with JMML/CMML. The aim of this study was to investigate the effects induced by trabectedin on cells derived from CMML and JMML patients and on a cellular model of the CMML, MV-4-11 cell line, in vitro and in vivo.

\section{MATERIALS AND METHODS}

Ethical clearance. Investigations on patients with JMML and CMML were approved by the Ethics Committees of the IRCCS Fondazione Maugeri, Pavia, and of the Fondazione IRCCS Policlinico San Matteo, Pavia, Italy. All procedures were carried out in accordance with the ethical standards of the Declaration of Helsinki. Written informed consensus was obtained from all patients. Animal experiments were reviewed and approved by the IRFMN (IRCCS Istituto di Ricerche Farmacologiche Mario Negri) Animal Care and Use Committee that includes 'ad hoc' members for ethical issues.

Drugs. Trabectedin was supplied by PharmaMar (Colmenar Viejo, Madrid, Spain), dissolved in DMSO at a concentration of $1 \mathrm{~mm}$ and stored at $-20^{\circ} \mathrm{C}$. 5-Azacitidine (5-AZA) was purchased from Sigma (St Louis, MO, USA). All the drugs were diluted in complete medium just before use.

Patients, sample collection and cell culture. The main clinical and haematological characteristics of 20 patients with CMML and 13 patients with JMML are reported in Supplementary Table 1. All patients had never received cytoreductive therapy before the enrollment in this study.

Malignant monocytes and CD34 + haematopoietic progenitor cells were isolated from peripheral blood/bone marrow mononuclear cells (MNCs) by immunomagnetic adsorption on Mini MACS separation columns using anti-CD14 and CD34 antibodies (Miltenyi Biotec, Bergisch Gladbach, Germany), respectively. For the antiproliferative assay the cells were maintained in X-VIVO 15 medium (Lonza Ltd, Basel, Switzerland) containing 10\% HyClone fetal bovine serum (FBS) Defined (Thermo Scientific, Waltham, MA, USA), 1\% L-glutamine (200 mM) and 1\% penicillin/streptomycin (Biowest, Nuaillé, France). The growth of CFU-GM colonies was evaluated using Methocult GF (Stem Cell Laboratories, Cambridge, MA, USA). Briefly, $2-4 \times 10^{4}$ MNCs were plated in $1 \mathrm{ml}$ methylcellulose, with $30 \%$ FCS, $10 \mathrm{ng} \mathrm{ml}^{-1}$ GM-CSF, $10 \mathrm{ng} \mathrm{ml}^{-1}$ IL-3 and $50 \mathrm{ng}$ IL-3 SCF. The number of colonies was scored with an inverted microscope after 14 days of culture at $37^{\circ} \mathrm{C}, 5 \% \mathrm{CO}_{2}$ in a fully humidified incubator. Inhibition of the in vitro growth of haematopoietic progenitors by trabectedin $(0.1,1$ and $5 \mathrm{nM})$ and 5-AZA $(0.1$ and $1 \mu \mathrm{M})$ was evaluated.

Cell lines culture and animal model. The MV-4-11 (Lange et al, 1987; Rucker et al, 2006), originally obtained from a childhood biphenotypic (B-myelomonocytic) leukaemia and THP-1 (Drexler et al, 2004), established from the peripheral blood of a 1-year-old boy with acute monocytic leukaemia, were used in this study. The cells were cultured in RPMI-1640 (Biowest) supplemented with $10 \%$ Hy-Clone FBS Defined (Thermo Scientific), 1\% L-glutamine $200 \mathrm{~mm}$ and $1 \%$ penicillin/streptomycin (Biowest). Cells were maintained at $37^{\circ} \mathrm{C}$ in a humidified atmosphere at $5 \% \mathrm{CO}_{2}$ in $\mathrm{T} 25 \mathrm{~cm}^{2}$ flasks (Iwaky Bibby Sterilin, Staffordshire, UK).

Female athymic NCr-nu/nu mice, 6-8 weeks old, were obtained from Harlan Laboratories (Udine, Italy). They were housed in the Institute's animal care facilities under specific pathogen-free conditions in individually ventilated cages and handled using aseptic procedures.

MV-4-11 tumour fragments were implanted subcutaneously in the right side of mice. Tumours were measured with a caliper and their weights $\left(1 \mathrm{~mm}^{3}=1 \mathrm{mg}\right)$ were calculated with the formula: length $\times(\text { width })^{2} / 2$. When tumour weight reached $150-200 \mathrm{mg}$, mice were randomised and treatment as started. 
Trabectedin was injected i.v. at the doses of $0.15 \mathrm{mg} \mathrm{kg}^{-1}$, every 7 days for three times. 5-AZA was given i.v. at the dose of $5 \mathrm{mg} \mathrm{kg}^{-1}$ every 3 days for five times. Each group comprised nine mice. Drug efficacy was calculated as $T / C \%$, where $T$ and $C$ are the mean tumour weights of treated and control groups, respectively.

Antiproliferative assay. The antiproliferative effect of the drugs on CMML or JMML primary cultures and on the MV-4-11 and THP-1 cell lines was evaluated with a standard growth inhibition assay.

CMML/JMML cells, at a concentration of 500000 cell per ml, MV-4-11 cell line at 30000 cell per $\mathrm{ml}$ and THP-1 cell line at 50000 cell per ml were seeded in 24-Multiwell plates (Iwaky Bibby Sterilin), and $24 \mathrm{~h}$ (CMML/JMML) and $48 \mathrm{~h}$ (cell lines) later were treated for $72 \mathrm{~h}$ with the drugs. Growth inhibition was recorded at 24,48 and $72 \mathrm{~h}$ of treatment by counting the number of cells with a Coulter Counter (Beckman Coulter, Pasadena, CA, USA).

Apoptosis. Apoptosis was determined on CMML or JMML cells, previously incubated with the anti-CD14 or CD34 antibody (Beckman Coulter, Brea, CA, USA) and on MV-4-11 and THP-1 cell lines, at different intervals during drug treatment by Annexin V-FITC/propidium iodide (PI) flow cytometric assay (Allavena et al, 2005) using a Gallios instrument (Beckman Coulter).

Gene expression profiling analysis. The gene expression profiling analysis was performed on 177 samples from 24 CMML cases and 30 samples from 8 JMML cases, and on MV-4-11 cells (Calura et al, 2013). At $24 \mathrm{~h}$ after treatment with trabectedin or 5-AZA (except for JMM samples), CMML, JMML and MV-4-11 cells were washed in PBS and pellets were stored at $-80^{\circ} \mathrm{C}$ until RNA extraction, using a miRNeasy Mini Kit (Qiagen, Venlo, The Netherlands), following the manufacturer's instruction. mRNA expression levels were examined by qRT-PCR using Applied Biosystems (Foster City, CA, USA) 7900HT. cDNA was generated from $200 \mathrm{ng}$ of purified total RNA using the High-Capacity cDNA Reverse Transcription Kit (Applied Biosystems), following the manufacturer's instructions. mRNA expression was analysed using QuantiFast SYBR Green PCR Master Mix (Qiagen) and dedicated primers (Supplementary Table 2); data were normalised using the geometric mean of four independent housekeeping genes (B2M, cyclophilin A, GAPDH and HPRT1). Experiments were run in duplicate for each case, to assess technical variability using 384-well reaction plates in an automatic liquid handling station (epMotion 5075LH; Eppendorf, Hamburg, Germany). Analysis was done by using the $2^{-\Delta \Delta \mathrm{Ct}}$ protocol and the medians were compared using the non-parametric Wilcoxon matched-pairs signed-rank test. Differences were considered statistically significant with a twotailed $P$-value $<0.05$. All tests were done using GraphPad Prism Version 6 (GraphPad Software, La Jolla, CA, USA).

Biparametric BrdU/DNA cell cycle analysis. The cell cycle phase perturbations induced by trabectedin on MV-4-11 cells were evaluated by biparametric BrdU/DNA flow cytometric analysis (Erba et al, 2001).

Statistical analysis. For the growth inhibition and growth of CFUGM colonies assay the arithmetic mean and the s.e. of number of viable cells were calculated. The ratio of viable cells between control and treated cells was computed; on log scale, an estimate of the s.e. of this ratio was obtained by the Delta method as:

$$
\sqrt{ }\left(\left(\sigma_{\mathrm{C}} / \mu_{\mathrm{C}}\right)^{2}+\left(\sigma_{\mathrm{T}} / \mu_{\mathrm{T}}\right)^{2}\right)
$$

where $\mu_{\mathrm{C}}$ and $\mu_{\mathrm{T}}$ are the sample means of the control and treated viable cells, respectively, and $\sigma_{\mathrm{C}}$ and $\sigma_{\mathrm{T}}$ are the sample s.e. of the control and treated viable cells, respectively. A random-effects model was used to estimate mean and 95\% CI of the percentage of dead cells.

\section{RESULTS}

In vitro pharmacological effect of trabectedin on CMML and JMML primary cells. We investigated the cytotoxic effect of trabectedin on $\mathrm{CD} 14+$ and, in selected cases, also CD34+ progenitors, malignant myelomonocytic cells from CMML and JMML patients. Table 1a reports the percentage of CMML and JMML dead cells after drug exposure. Trabectedin had a potent cytotoxic effect in a dose-dependent manner in both disorders, greater than 5-AZA.

Clonogenic growth of CFU-GM was assessed in a classical semisolid assay in the presence of increasing concentrations of trabectedin. In CMML cells, trabectedin caused a mild inhibition of CFU-GM growth at $0.1 \mathrm{nM}$, increasing to $40 \%$ at $1 \mathrm{nM}$ and reaching $100 \%$ at $5 \mathrm{nM}$, regardless of the cell source used (PB or $\mathrm{BM})$. In JMML cells, strong inhibition of the spontaneous growth of CFU-GM was also observed in the presence of trabectedin. However, differently from CMML, the CFU-GM growth inhibition was already maximal at $1 \mathrm{~nm}$ (Table $1 \mathrm{~b})$.

\begin{tabular}{|c|c|c|c|}
\hline & Trab $0.1 \mathrm{~nm}$ & Trab $1 \mathrm{~nm}$ & Trab $5 \mathrm{~nm}$ \\
\hline \multicolumn{4}{|l|}{ CMML } \\
\hline $\begin{array}{l}\text { No. of cases } \\
\text { Mean }(\%, 95 \% \mathrm{Cl}) \\
\text { Range (\%) }\end{array}$ & $\begin{array}{c}16 \\
12(8-16) \\
5-19\end{array}$ & $\begin{array}{c}16 \\
40(30-49) \\
10-79\end{array}$ & $\begin{array}{c}16 \\
100(100-100) \\
92-100\end{array}$ \\
\hline \multicolumn{4}{|l|}{ JMML } \\
\hline $\begin{array}{l}\text { No. of cases } \\
\text { Mean }(\%, 95 \% \mathrm{Cl}) \\
\text { Range }(\%)\end{array}$ & $\begin{array}{c}5 \\
13(4-21) \\
11-20\end{array}$ & $\begin{array}{c}5 \\
100(99-100) \\
95-100\end{array}$ & $\begin{array}{c}5 \\
100(100-100) \\
100-100\end{array}$ \\
\hline
\end{tabular}

Abbreviations: $\mathrm{Cl}=$ confidence interval; $\mathrm{CFU}-\mathrm{GM}=$ colony forming unit-granulocyte, macrophage; $\mathrm{CMML}=$ chronic myelomonocytic leukaemia; JMML = juvenile myelomonocytic leukaemia; $T r a b=$ trabectedin

Table 1a. Percentages of cell growth inhibition after trabectedin or 5-AZA treatment in CMML and JMML samples

\begin{tabular}{|c|c|c|c|c|c|c|}
\hline & Trab $0.5 \mathrm{~nm}$ & Trab $1 \mathrm{~nm}$ & Trab $5 \mathrm{~nm}$ & 5-AZA $0.5 \mu \mathrm{M}$ & 5-AZA $1 \mu \mathrm{M}$ & 5-AZA $2.5 \mu \mathrm{M}$ \\
\hline \multicolumn{7}{|l|}{ CMML } \\
\hline $\begin{array}{l}\text { No. of cases } \\
\text { Mean }(\%, 95 \% \mathrm{Cl}) \\
\text { Range }(\%)\end{array}$ & $\begin{array}{c}27 \\
21(16-25) \\
0-60\end{array}$ & $\begin{array}{c}28 \\
34(28-40) \\
4-82 \\
\end{array}$ & $\begin{array}{c}29 \\
74(68-78) \\
17-98\end{array}$ & $\begin{array}{c}21 \\
13(6-19) \\
0-46\end{array}$ & $\begin{array}{c}21 \\
18(12-25) \\
0-51\end{array}$ & $\begin{array}{c}22 \\
19(11-26) \\
0-75\end{array}$ \\
\hline \multicolumn{7}{|l|}{ JMML } \\
\hline $\begin{array}{l}\text { No. of cases } \\
\text { Mean }(\%, 95 \% \mathrm{Cl}) \\
\text { Range }(\%)\end{array}$ & $\begin{array}{c}14 \\
9(1-17) \\
0-37\end{array}$ & $\begin{array}{c}17 \\
16(9-22) \\
0-40\end{array}$ & $\begin{array}{c}19 \\
50(43-57) \\
0-96\end{array}$ & $\begin{array}{c}12 \\
13(3-23) \\
0-48\end{array}$ & $\begin{array}{c}13 \\
16(9-23) \\
0-59\end{array}$ & $\begin{array}{c}13 \\
14(8-20) \\
0-60\end{array}$ \\
\hline
\end{tabular}


A
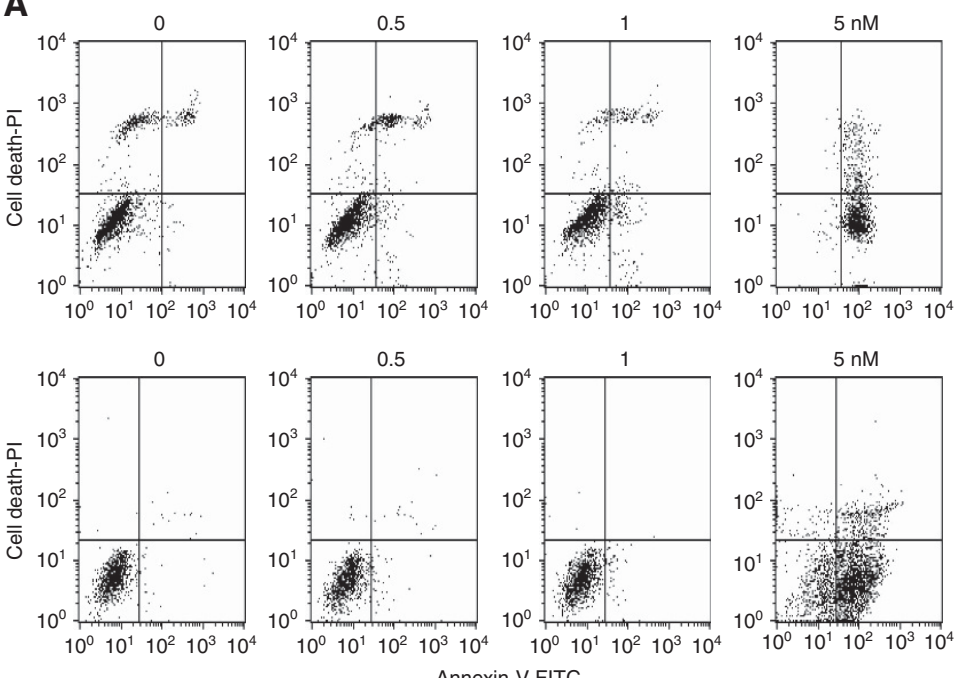
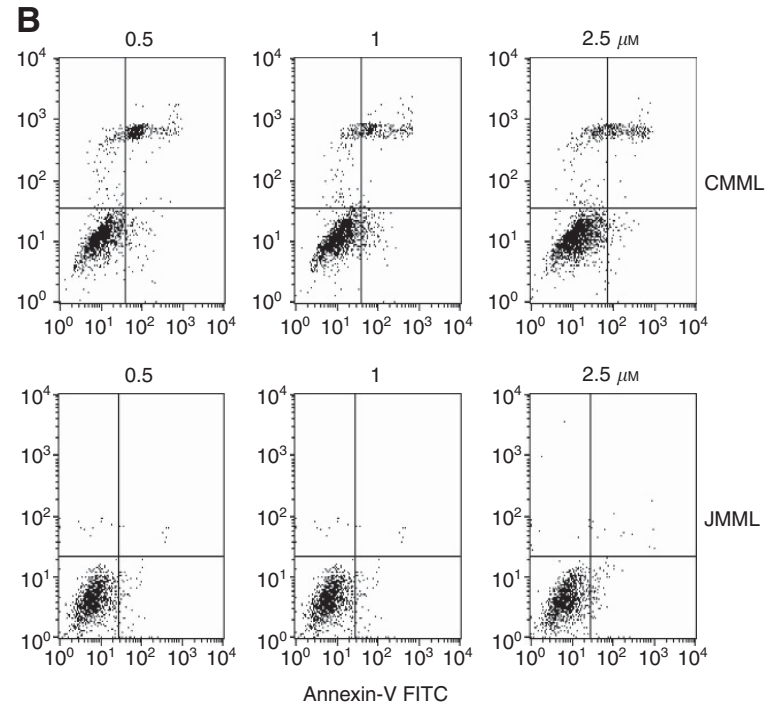

Figure 1. Biparametric Annexin V-FITC/PI flow cytometric analysis. Biparametric Annexin V-FITC/PI flow cytometric analysis on CMML and JMML cells after trabectedin (A) or 5-AZA (B). A representative example of CMML and JMML is shown at $72 \mathrm{~h}$ treatment. R1, viable cells; R2, early apoptotic cells; R3, late apoptotic cells; and R4, necrotic cells.

Table 2. Effect of trabectedin and 5-AZA on the expression profile of selected genes in CMML cells

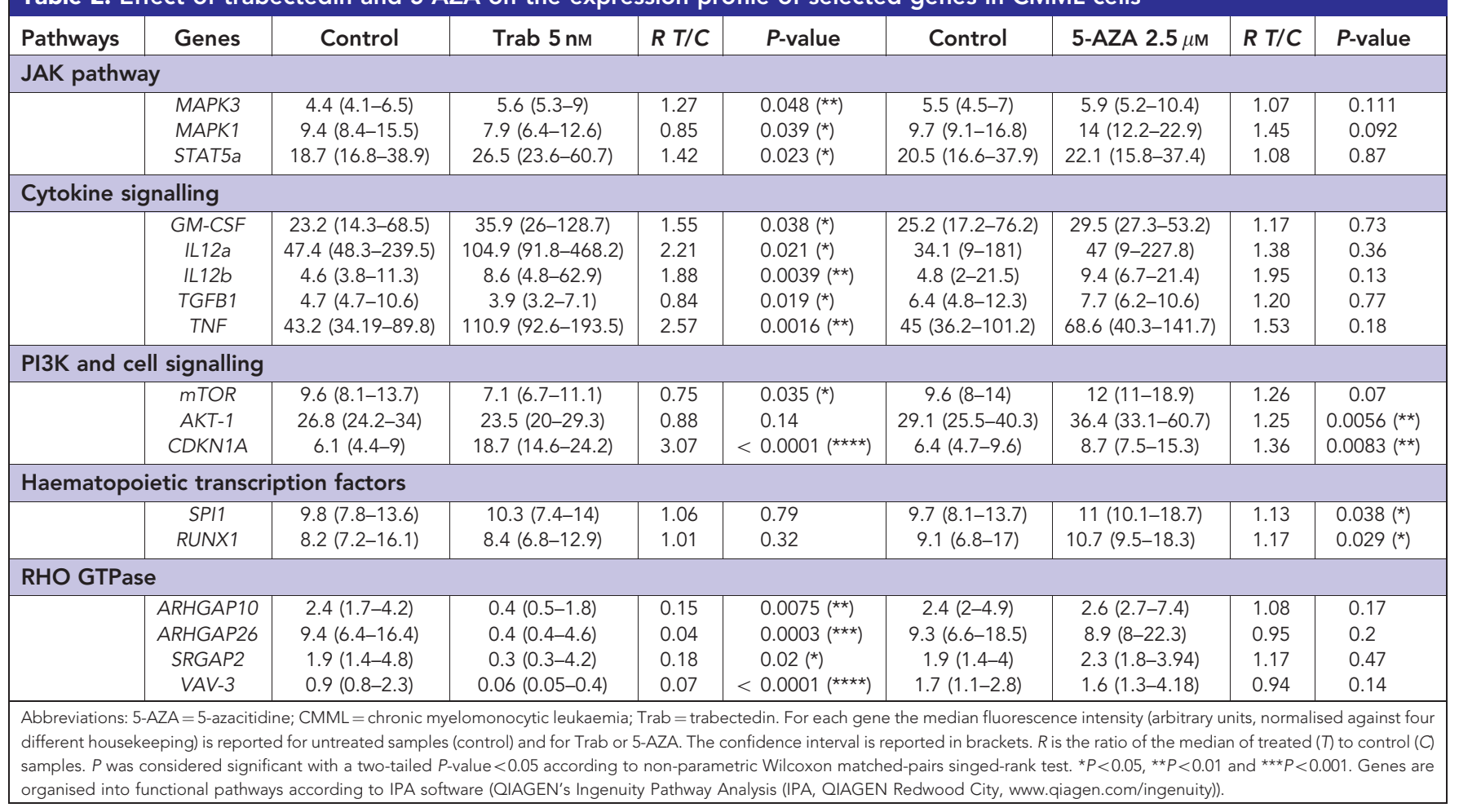

The mechanism of cell death induced by trabectedin and 5-AZA was investigated 24, 48 and $72 \mathrm{~h}$ during drug treatment in $\mathrm{CD} 14+$ and $\mathrm{CD} 34+$ malignant cells from CMML/JMML patients. Figure 1 illustrates representative experiments performed on CD14 + myelomonocytic cells from two patients with CMML and JMML, in which the biparametric Annexin V/PI flow cytometric assay was done after $72 \mathrm{~h}$ of continuous treatment with the two drugs. In both CMML and JMML cells, trabectedin had the strongest apoptotic effect at $5 \mathrm{~nm}$ (about $80 \%$ of cells were apoptotic), whereas at lower doses it induced apoptosis in smaller fractions of cells. 5-AZA at the highest dose of $2.5 \mu \mathrm{M}$ only caused apoptosis in $25 \%$ and $15 \%$ of CMML and JMML cells, respectively.
Gene expression profiling analysis after trabectedin exposure on CMML and JMML primary cells. Trabectedin upregulated several genes in CMML malignant cells, including $M A P K 3$ and STAT5a (belonging to the JAK pathway), GM-CSF, IL12a, IL12b and TNF (belonging to the cytokine signalling pathway) and CDKN1A (belonging to the cell signalling pathway), as shown in Table 2. However, the strongest effects on gene expression were on the Rho GTPase pathway (belonging to the RAS superfamily). The expression of all the genes of the Rho GTPase pathway, that is, ARHGAP10, ARHGAP26, $S R G A P 2$ and $V A V-3$, was drastically reduced from 5 to more than 25 times. 5-AZA affected fewer genes in MDS/MPN 
Table 3. Effect of trabectedin on the expression profile of selected genes in JMML cells

\begin{tabular}{|c|c|c|c|c|c|}
\hline Pathways & Genes & Control & Trab 5 nм & $R T / C$ & $P$-value \\
\hline \multicolumn{6}{|c|}{ JAK pathway } \\
\hline & MAPK3 & $12(9.7-19.4)$ & $20.4(12.8-35.2)$ & 1.70 & $0.0313\left(^{*}\right)$ \\
\hline & MAPK1 & $6.8(3.4-9.7)$ & $3.5(3-5.2)$ & 0.52 & $0.0469\left(^{*}\right)$ \\
\hline \multicolumn{6}{|c|}{ Cytokine signalling } \\
\hline & BMP4 & $0.2(0.2-0.3)$ & $0.5(-0.2-2.2)$ & 2.65 & $0.0313\left(^{*}\right)$ \\
\hline \multicolumn{6}{|c|}{ Cell signalling } \\
\hline & CDKN1A & $105.6(29.9-193.9)$ & $285.1(136.1-48)$ & 2.70 & $0.0313\left(^{*}\right)$ \\
\hline \multicolumn{6}{|c|}{ RHO GTPase } \\
\hline & ARHGAP10 & $21.3(-12.4-90.5)$ & $1.5(-1.4-8.6)$ & 0.07 & $0.0156\left(^{*}\right)$ \\
\hline & ARHGAP26 & 56.7 (13.6-79.9) & $1.2(-0.5-5.4)$ & 0.02 & $0.0313\left(^{*}\right)$ \\
\hline & SRGAP2 & $21.4(10.7-38.4)$ & $2.3(1-4.5)$ & 0.11 & $0.0156\left(^{*}\right)$ \\
\hline & VAV-3 & $14.2(10.1-18.6)$ & $0.3(0.1-1.3)$ & 0.02 & $0.0156(*)$ \\
\hline \multicolumn{6}{|c|}{ 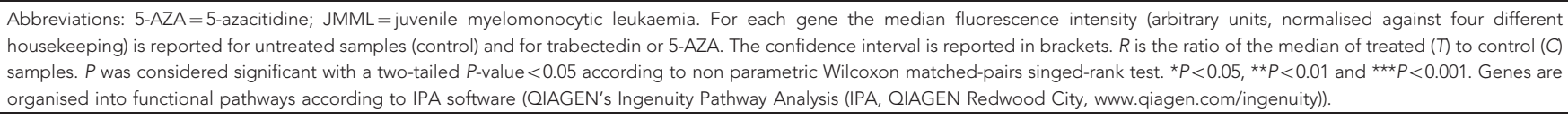 } \\
\hline
\end{tabular}

cells, including upregulation of $A K T-1, C D K N 1 A, S P I 1$ and RUNX1 expression, whereas the Rho GTPase pathway was not affected (Table 2).

The effects of trabectedin on JMML malignant cells are shown in Table 3. Similar to that in CMML, in JMML myelomonocytic cells treated with trabectedin, MAPK3 and MAPK1 were respectively up- and downregulated, BMP4 and CDKN1A levels were more than double than control, whereas the expression of genes belonging to the Rho GTPase pathway was drastically reduced. Because of the limited number of cells obtained from JMML samples, we could not assess the effect of 5-AZA on gene expression profiling.

In vitro and in vivo pharmacological effect of trabectedin on MV-4-11 and THP-1 cells. As there are obvious limitations in the availability of fresh primary cells from CMML and JMML patients, and a cellular model that expresses $100 \%$ of the features of these diseases is not available, we decided to use the MV-4-11 cell line, established from a patient with biphenotypic B-myelomonocytic leukaemia and expressing markers of myelomonocytic differentiation, such as $\mathrm{CD}^{-}, \mathrm{CD}^{-} 0^{-}, \mathrm{CD} 4^{+}, \mathrm{CD}_{3} 3^{+}, \mathrm{CD} 14^{+}$and THP-1 cell line expressing $\mathrm{CD} 3^{-}, \mathrm{CD}_{3} 3^{+}, \mathrm{CD} 4^{+}, \mathrm{CD}_{1}{ }^{-}$and $\mathrm{CD} 34^{-}$ as a surrogate for further in vitro investigations and for the generation of an animal model that could be exploited for assessing in vivo the pharmacological activity of trabectedin. On MV-4-11 and THP-1 cells, trabectedin had a stronger growth inhibitory effect than 5-AZA (a conventional treatment for MDS/MPN patients, used for comparison in these experiments) with $\mathrm{IC}_{50}$ at $72 \mathrm{~h}$, respectively, $1 \mathrm{~nm}$ and $2.5 \mu \mathrm{M}$ (Figure $2 \mathrm{~A}$ for MV-4-11 and Figure 2C for THP-1 cells). As shown on CMML or JMML cells, trabectedin had a marked time- and dose-dependent apoptotic effect also on MV-4-11 and THP-1 cell lines (Figure 2B and $\mathrm{D}$, respectively), whereas 5-AZA induced apoptosis only in a small proportion of cells only on MV-4-11 and not on THP-1 cells (Figure $2 \mathrm{~B}$ and $\mathrm{D}$, respectively).

BrdU/DNA biparametric cell cycle analysis was done on MV-4-11, to examine the cell cycle phase perturbations induced by trabectedin. The drug caused a delay in crossing all the cell cycle phases in both BrdU-positive and -negative cell fractions (Supplementary Figure 1). The detection of DNA strand breaks generated during apoptosis, by biparametric flow cytometric TUNEL/DNA assay, showed that after trabectedin the majority of apoptotic cells were in the G1/S boundary phase (data not shown).

We then investigated the gene expression profiling changes after drug treatment on MV-4-11 cell line (Figure 2E). Trabectedin $5 \mathrm{~nm}$ strongly upregulated IL12b, CDKN1A (p21), whereas genes belonging to the Rho GTPase pathway (ARHGAP10, ARHGAP26, $S R G A P 2$ and $V A V-3)$ were downregulated. 5-AZA upregulated the expression of genes encoding for IL12a and TGFB1, mTOR and AKT, PU.1 and RUNX1, ARHGAP26 (Figure 2F).

Finally, we evaluated the in vivo antitumour activity of trabectedin in a MV-4-11 mouse model (Figure 3). Trabectedin inhibited tumour growth, whereas 5-AZA had no such effect the tumours treated with this drug grow similar to the control (best T/ C on day 27 were, respectively $36.1 \%$ and $95 \%$ ).

\section{DISCUSSION}

This study provides evidence of strong cytotoxic activity of trabectedin in malignant cells and haematopoietic progenitors from CMML and JMML patients, as well as in cellular and mouse models of myelomonocytic leukaemia.

MDS/MPN neoplasms are diseases with a poor clinical outcome and significant unmet medical need (Vardiman et al, 2009). Both involve a high risk of progression during the natural history of the disease. In patients not eligible for transplantation, neither intensive nor moderate chemotherapy consistently improves the clinical outcome. In JMML, inhibition of activated RAS would appear to be a logical therapeutic strategy (Locatelli et al, 2005; Emanuel, 2008; Loh, 2010, 2011; Cazzola et al, 2013; Itzykson and Solary, 2013; Itzykson et al, 2013; Patnaik et al, 2014; Locatelli and Niemeyer, 2015; Stieglitz et al, 2015). However, farnesyltransferase inhibitors induce only partial and transient clinical responses. CMML patients may benefit from treatment with 5-AZA or hydroxyurea, but unfortunately neither of these substantially modify the natural history of the disease (Patnaik and Tefferi, 2016).

Selective macrophage and myelomonocytic cell compartment targeting is a key component of the antitumour activity of trabectedin, supporting the hypothesis that this drug may have an antitumour effect on MDS/MPN (Germano et al, 2013; D'Incalci et al, 2014).

We observed that trabectedin induces apoptosis in malignant cells from both CMML and JMML patients, and inhibits the clonogenic growth of CFU-GM at concentrations in the range of 1-5 nM, which are pharmacologically reasonable, as they are achieved in plasma of patients receiving the drug at tolerable doses (Perez-Ruixo et al, 2007; Sessa et al, 2009a, 2009b; Ceriani et al, 2015).

The potent cytotoxic effect of trabectedin in patient-derived CMML or JMML cells is in keeping with previous observations in 
$\mathbf{A}_{1}$

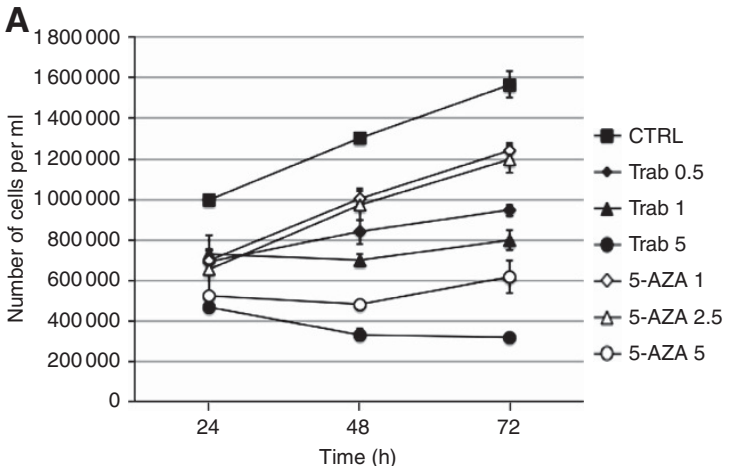

C

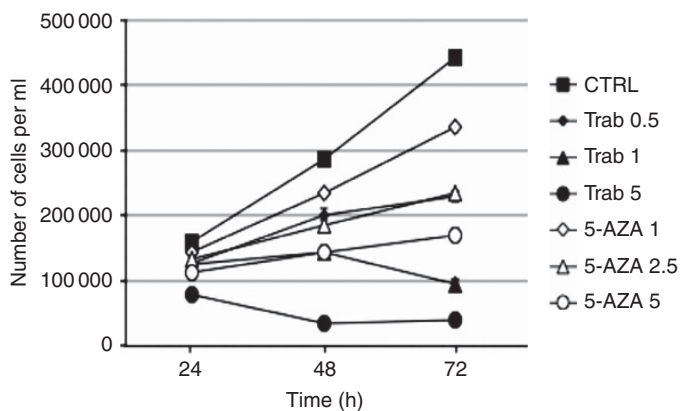

E

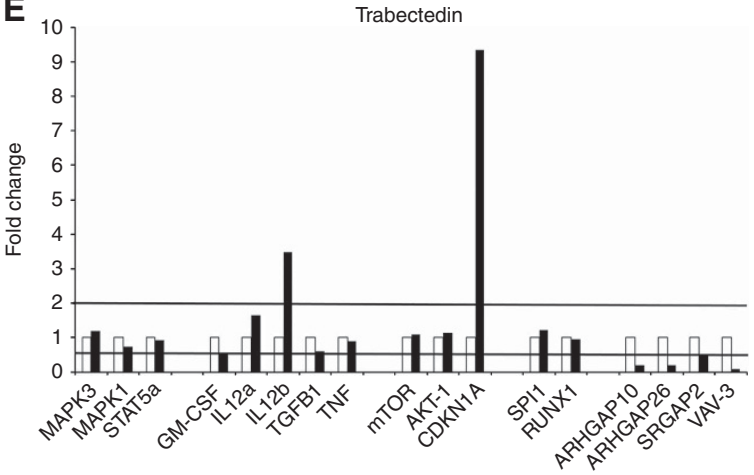

B
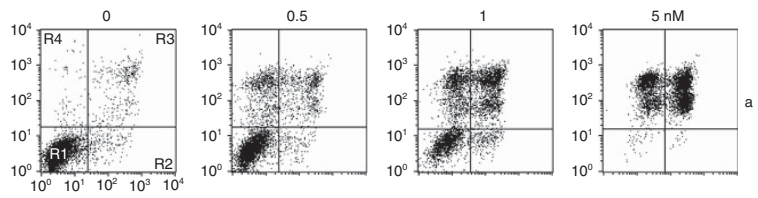

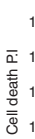
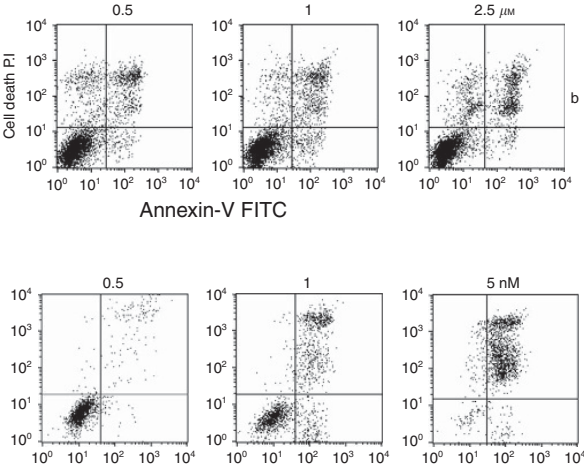

Annexin-V FITC
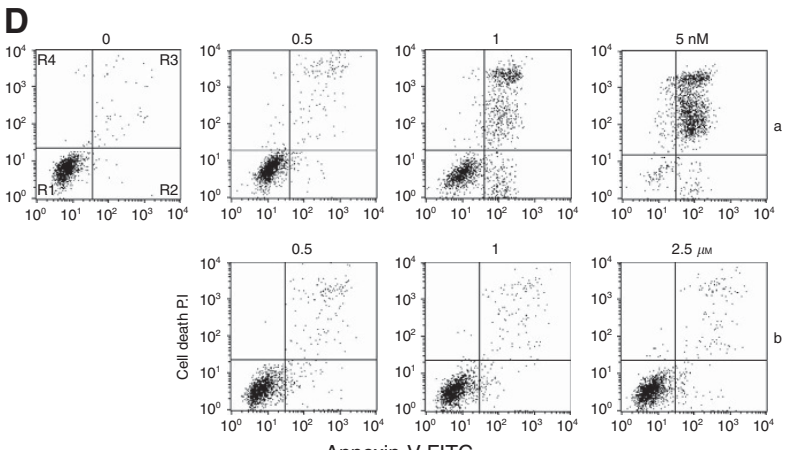

F

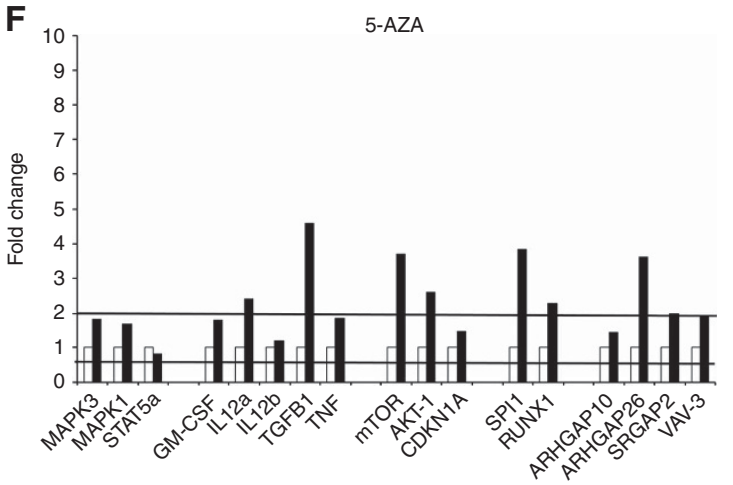

Figure 2. Effect of $72 \mathrm{~h}$ trabectdin or 5-AZA exposure on MV-4-11 and THP-1 cell growth. (A) Effect of $72 \mathrm{~h}$ trabectedin or 5-AZA exposure on MV-4-11 cell growth at different intervals during treatment. The data are the mean of three independent experiments; bars indicate the s.d. (B) Biparametric Annexin V-FITC/PI flow cytometric analysis on MV-4-11 cells after $72 \mathrm{~h}$ trabectedin (a) or 5-AZA (b) treatment. R1, viable cells; R2, early apoptotic cells; R3, late apoptotic cells; and R4, necrotic cells. (C) Effect of $72 \mathrm{~h}$ trabectedin or 5-AZA exposure on THP-1 cell growth at different intervals during treatment. The data are the mean of three independent experiments; bars indicate the s.d. (D) Biparametric Annexin V-FITC/PI flow cytometric analysis on THP-1 cells after $72 \mathrm{~h}$ trabectedin (a) or 5-AZA (b) treatment. R1, viable cells; R2, early apoptotic cells; R3, late apoptotic cells; and R4, necrotic cells. (E) Gene expression in MV-4-11 cells at $24 \mathrm{~h} 5 \mathrm{~nm}$ trabectedin treatment. Data were analysed by the DDCT method and expressed as-fold changes (arbitrary units) compared with untreated control cells (white bars), set as 1. (F) Gene expression in MV-411 cells at $24 \mathrm{~h} 2.5 \mu \mathrm{m}$ 5-AZA treatment. Data were analysed by the DDCT method and expressed as-fold changes (arbitrary units) compared to untreated control cells (white bars), set as 1.

normal monocytes and macrophages. The pro-apoptotic effect of trabectedin on mononuclear phagocytes was related to activation of the extrinsic apoptotic pathway and was selective for myelomonocytic cells, as neutrophils and lymphocytes were not affected (Germano et al, 2013). The sensitivity of the myelomonocytic lineage was ascribed to the high expression of signalling TRAIL receptors of these cells and the lack of decoy R3 receptors, which are expressed in neutrophils and lymphocytes (Germano et al, 2013). Mechanistically, this has been explained by the differential expression of death receptors (TRAIL-Rs) on cell membranes: monocytes express higher levels of the functional receptors (TRAIL-R1 and R2), which are poorly expressed by neutrophils and lymphocytes. Furthermore, the latter express high levels of TRAIL-R3, a decoy receptor blocking apoptosis, which is instead not expressed on monocytes (Germano et al, 2013; Liguori et al, 2016). Our group previously published that normal human monocytes are susceptible to the cytotoxic activity of trabectedin and undergo caspase-dependent intrinsic apoptosis at doses of 5-10 nM, for relatively long exposures $(24-48 \mathrm{~h}$; Germano et al, 2013). Monocyte depletion in vivo in mouse experiments is transient and not total: about $50 \%$ of monocytes or tissue macrophages are depleted $48 \mathrm{~h}$ after administration.

It may be legitimate to ask the question if the monocyte depletion induced by trabectedin cause a greater vulnerability to infections. However, the clinical experience with trabectedin does not suggest a particularly high incidence of infections in patients receiving the drug and this can be explained considering that monocytes are continuously produced in the bone marrow and 


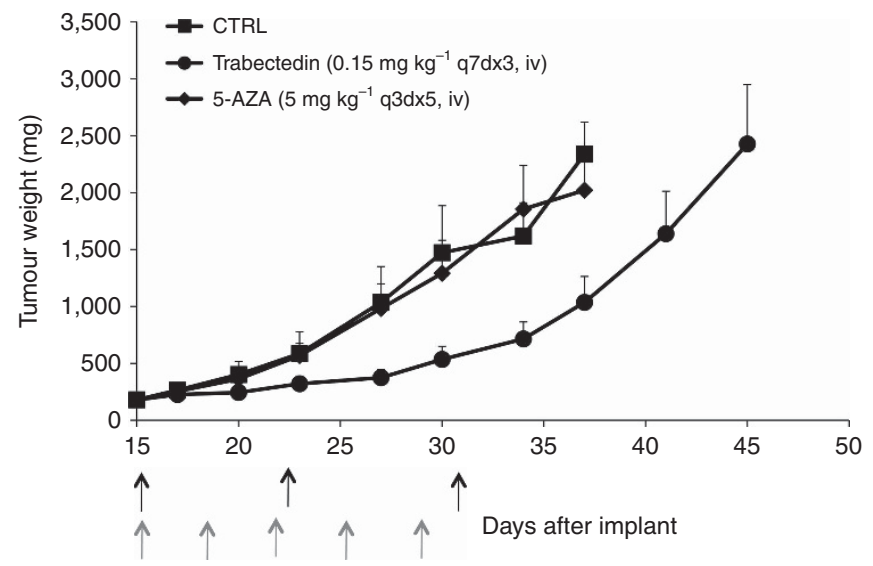

Figure 3. Antitumour activity of trabectedin compared with 5-AZA in MV-4-11 mice. The arrows on the X-axis indicate the time of treatment with trabectedin (black) or 5-AZA (grey).

conveyed in the blood stream, so their level in blood are only transiently decreased after trabectedin treatment. In addition, the prime line of defense against bacteria is assured by neutrophils, which are not affected by trabectedin; viral infections by lymphocytes, which are also not killed.

Unfortunately, because of the limited number of cells obtained from CMML and JMML samples, we could not assess the TRAILreceptor induction on CMML-JMML cells derived from patients.

The cytotoxic effect of trabectedin against CMML/JMML malignant cells did not appear to be related to cell cycle blockade. In contrast to what has been reported in cell lines derived from patients with sarcomas or ovarian carcinomas (Erba et al, 2001; Tavecchio et al, 2007, 2008; Germano et al, 2010), trabectedin did not cause major cell cycle perturbations in MDS/MPN cells, implying that the action against these leukaemia cells is not exerted through an antiproliferative effect. Monocytes and macrophages, which are very sensitive to trabectedin, are quiescent cells, indicating that trabectedin, in contrast to the majority of cytotoxic drugs, does not target DNA synthesis, at least in myelomonocytic cells. In JMML/CMML cells the drug can affect transcription regulation, as demonstrated in some sarcomas (Di Giandomenico et al, 2014), and also suggested by the fact that the transcription of genes encoding for some cytokines and chemokines is downregulated in myelomonocytic cells exposed to trabectedin (Germano et al, 2013).

In our study, trabectedin was able to affect the expression of several genes involved in different pathways. Compared with the action of 5-AZA, trabectedin was able to induce a mild, but significant, upregulation both of genes of the JAK pathway and of genes of the cytokine signalling pathways (Table 2). At variance, trabectedin exerted a slight downregulation of $m T O R$ and $A K T-1$ genes, whereas both trabectedin and 5-AZA upregulated CDKN1A expression. However, the most important gene expression changes in myelomonocytic malignant cells from both CMML and JMML patients exposed to trabectedin involved significant downregulation of the RhoGTPase pathway. The role of RhoGTPase proteins in haematopoiesis has been amply described: increased activity of these proteins leads to enhanced proliferation and survival in normal and malignant myeloid cells (Kourlas et al, 2000; EtienneManneville and Hall, 2002; Mulloy et al, 2010). Recent observations in our laboratory have indicated that in normal myelomonocytic cells exposed to trabectedin the genes whose expression was changed most were those encoding for RhoGTPase (unpublished data). Therefore, the fact that also in CMML and JMML genes encoding RhoGTPase were strongly downregulated by trabectedin reinforces the idea that the drug's effect against these leukaemias is lineage-specific and is not necessarily due to the action on particular genes involved in the neoplastic transformation of the leukaemic cells.

Interestingly, RhoGTPases are closely related to the RAS gene and share considerable structure and function similarities with RAS and other RAS-related small GTPases (Bourne et al, 1991; Troeger and Williams, 2013). Considering that activating mutations of members of KRAS and NRAS have been reported to be involved in JMML and CMML pathogenesis, and that the GM-CSF hypersensitivity that characterises both JMML and CMML haematopoietic progenitors results from continuous activation of the GM-CSF receptor-RAS-RAF-MEK-ERK signal transduction pathway (de Vries et al, 2010), and of the STAT5 pathway (Padron et al, 2013), respectively, the downregulation of RhoGTPase we observed in this disease may explain the in vitro inhibitory effect of trabectedin on the spontaneous growth of CFU-GM but also positions trabectedin as potential new drug for the treatment of this disease. In this regard, the fact that farnesyltransferase inhibitors, which are known to act on RAS proteins, also target Rho proteins, while reinforcing the concept that inhibition of these pathways is of major importance in CMML also brings support to new therapeutic strategies based on the use of these inhibitors for targeting specifically Rho proteins in patients with CMML, including those who are non-mutated in KRAS/NRAS.

The data presented here are of substantial potential interest, as they provide the rationale for testing trabectedin in clinical trials in CMML/JMML patients. With a view to the potential clinical applications it was important to do additional in vivo experiments to assess the antitumour activity of trabectedin at tolerable doses. We did these in the MV-4-11 myelomonocytic cell line growing in vivo in immunodeficient mice. The results were certainly encouraging as trabectedin showed remarkable antitumour activity in this model.

In conclusion, the natural marine product trabectedin, previously found to have selective cytotoxic effects on myelomonocytic cells, has strong apoptotic effects in leukaemic cells from patients with CMML or JMML, suggesting it would be worth investigating it on these leukaemias for which there is an urgent need of effective drugs as they are insensitive to all the current therapeutic agents.

\section{ACKNOWLEDGEMENTS}

We thank the Italian Association for Cancer Research (Maurizio D'Incalci, AIRC Project N.6595) and Fondazione 'Sofia Luce Rebuffat' (Marco Zecca).

\section{CONFLICT OF INTEREST}

Maurizio D'Incalci has received honorarium to participate in a scientific board of PhamaMar. Carlos M Galmarini is an employee of PharmaMar, which produces trabectedin.

\section{REFERENCES}

Allavena P, Mantovani A (2012) Immunology in the clinic review series; focus on cancer: tumour-associated macrophages: undisputed stars of the inflammatory tumour microenvironment. Clin Exp Immunol 167: 195-205.

Allavena P, Signorelli M, Chieppa M, Erba E, Bianchi G, Marchesi F, Olimpio CO, Bonardi C, Garbi A, Lissoni A, de Braud F, Jimeno J, D'Incalci M (2005) Anti-inflammatory properties of the novel antitumor agent yondelis (trabectedin): inhibition of macrophage differentiation and cytokine production. Cancer Res 65: 2964-2971. 
Bourne HR, Sanders DA, McCormick F (1991) The GTPase superfamily: conserved structure and molecular mechanism. Nature 349: 117-127.

Calura E, Fruscio R, Paracchini L, Bignotti E, Ravaggi A, Martini P, Sales G, Beltrame L, Clivio L, Ceppi L, Di Marino M, Fuso Nerini I, Zanotti L, Cavalieri D, Cattoretti G, Perego P, Milani R, Katsaros D, Tognon G, Sartori E, Pecorelli S, Mangioni C, D’Incalci M, Romualdi C, Marchini S (2013) MiRNA landscape in stage I epithelial ovarian cancer defines the histotype specificities. Clin Cancer Res 19: 4114-4123.

Cazzola M, Della Porta MG, Malcovati L (2013) The genetic basis of myelodysplasia and its clinical relevance. Blood 122: 4021-4034.

Ceriani L, Ferrari M, Zangarini M, Licandro SA, Bello E, Frapolli R, Falcetta F, D'Incalci M, Libener R, Grosso F, Aviles P, Zucchetti M (2015) HPLC-MS/ MS method to measure trabectedin in tumors: preliminary PK study in a mesothelioma xenograft model. Bioanalysis 7: 1831-1842.

D'Incalci M, Galmarini CM (2010) A review of trabectedin (ET-743): a unique mechanism of action. Mol Cancer Ther 9: 2157-2163.

D'Incalci M, Badri N, Galmarini CM, Allavena P (2014) Trabectedin, a drug acting on both cancer cells and the tumour microenvironment. Br J Cancer 111: 646-650.

Damia G, Silvestri S, Carrassa L, Filiberti L, Faircloth GT, Liberi G, Foiani M, D'Incalci M (2001) Unique pattern of ET-743 activity in different cellular systems with defined deficiencies in DNA-repair pathways. Int J Cancer 92: 583-588.

de Vries AC, Zwaan CM, van den Heuvel-Eibrink MM (2010) Molecular basis of juvenile myelomonocytic leukemia. Haematologica 95: 179-182.

Demetri GD, Chawla SP, von Mehren M, Ritch P, Baker LH, Blay JY, Hande KR, Keohan ML, Samuels BL, Schuetze S, Lebedinsky C, Elsayed YA, Izquierdo MA, Gomez J, Park YC, Le Cesne A (2009) Efficacy and safety of trabectedin in patients with advanced or metastatic liposarcoma or leiomyosarcoma after failure of prior anthracyclines and ifosfamide: results of a randomized phase II study of two different schedules. J Clin Oncol 27: 4188-4196.

Demetri GD, von Mehren M, Jones RL, Hensley ML, Schuetze SM, Staddon A, Milhem M, Elias A, Ganjoo K, Tawbi H, Van Tine BA, Spira A, Dean A, Khokhar NZ, Park YC, Knoblauch RE, Parekh TV, Maki RG, Patel SR (2016) Efficacy and safety of trabectedin or dacarbazine for metastatic liposarcoma or leiomyosarcoma after failure of conventional chemotherapy: results of a Phase III Randomized Multicenter Clinical Trial. J Clin Oncol 34: 786-793.

DeNardo DG, Barreto JB, Andreu P, Vasquez L, Tawfik D, Kolhatkar N, Coussens LM (2009) CD4(+) T cells regulate pulmonary metastasis of mammary carcinomas by enhancing protumor properties of macrophages. Cancer Cell 16: 91-102.

Di Giandomenico S, Frapolli R, Bello E, Uboldi S, Licandro SA, Marchini S, Beltrame L, Brich S, Mauro V, Tamborini E, Pilotti S, Casali PG, Grosso F, Sanfilippo R, Gronchi A, Mantovani R, Gatta R, Galmarini CM, SousaFaro JM, D'Incalci M (2014) Mode of action of trabectedin in myxoid liposarcomas. Oncogene 33: 5201-5210.

Drexler HG, Quentmeier H, MacLeod RA (2004) Malignant hematopoietic cell lines: in vitro models for the study of MLL gene alterations. Leukemia 18: $227-232$.

Emanuel PD (2008) Juvenile myelomonocytic leukemia and chronic myelomonocytic leukemia. Leukemia 22: 1335-1342.

Erba E, Bergamaschi D, Bassano L, Damia G, Ronzoni S, Faircloth GT, D'Incalci M (2001) Ecteinascidin-743 (ET-743), a natural marine compound, with a unique mechanism of action. Eur J Cancer 37: 97-105.

Etienne-Manneville S, Hall A (2002) Rho GTPases in cell biology. Nature 420: 629-635.

Friedman D, Hu Z, Kolb EA, Gorfajn B, Scotto KW (2002) Ecteinascidin-743 inhibits activated but not constitutive transcription. Cancer Res 62: 3377-3381.

Germano G, Frapolli R, Belgiovine C, Anselmo A, Pesce S, Liguori M, Erba E, Uboldi S, Zucchetti M, Pasqualini F, Nebuloni M, van Rooijen N, Mortarini R, Beltrame L, Marchini S, Fuso Nerini I, Sanfilippo R, Casali PG, Pilotti S, Galmarini CM, Anichini A, Mantovani A, D'Incalci M, Allavena P (2013) Role of macrophage targeting in the antitumor activity of trabectedin. Cancer Cell 23: 249-262.

Germano G, Frapolli R, Simone M, Tavecchio M, Erba E, Pesce S, Pasqualini F, Grosso F, Sanfilippo R, Casali PG, Gronchi A, Virdis E, Tarantino E, Pilotti S, Greco A, Nebuloni M, Galmarini CM, Tercero JC, Mantovani A, D'Incalci M, Allavena P (2010) Antitumor and antiinflammatory effects of trabectedin on human myxoid liposarcoma cells. Cancer Res 70: 2235-2244.
Grosso F, Jones RL, Demetri GD, Judson IR, Blay JY, Le Cesne A, Sanfilippo R, Casieri P, Collini P, Dileo P, Spreafico C, Stacchiotti S, Tamborini E, Tercero JC, Jimeno J, D'Incalci M, Gronchi A, Fletcher JA, Pilotti S, Casali PG (2007) Efficacy of trabectedin (ecteinascidin-743) in advanced pretreated myxoid liposarcomas: a retrospective study. Lancet Oncol 8: 595-602.

Itzykson R, Kosmider O, Renneville A, Gelsi-Boyer V, Meggendorfer M, Morabito M, Berthon C, Ades L, Fenaux P, Beyne-Rauzy O, Vey N, Braun T, Haferlach T, Dreyfus F, Cross NC, Preudhomme C, Bernard OA, Fontenay M, Vainchenker W, Schnittger S, Birnbaum D, Droin N, Solary E (2013) Prognostic score including gene mutations in chronic myelomonocytic leukemia. J Clin Oncol 31: 2428-2436.

Itzykson R, Solary E (2013) An evolutionary perspective on chronic myelomonocytic leukemia. Leukemia 27: 1441-1450.

Kourlas PJ, Strout MP, Becknell B, Veronese ML, Croce CM, Theil KS, Krahe R, Ruutu T, Knuutila S, Bloomfield CD, Caligiuri MA (2000) Identification of a gene at 11q23 encoding a guanine nucleotide exchange factor: evidence for its fusion with MLL in acute myeloid leukemia. Proc Natl Acad Sci USA 97: 2145-2150.

Lange B, Valtieri M, Santoli D, Caracciolo D, Mavilio F, Gemperlein I, Griffin C, Emanuel B, Finan J, Nowell P (1987) Growth factor requirements of childhood acute leukemia: establishment of GM-CSFdependent cell lines. Blood 70: 192-199.

Liguori M, Buracchi C, Pasqualini F, Bergomas F, Pesce S, Sironi M, Grizzi F, Mantovani A, Belgiovine C, Allavena P (2016) Functional TRAIL receptors in monocytes and tumor-associated macrophages: a possible targeting pathway in the tumor microenvironment. Oncotarget 7: 41662-41676.

Locatelli F, Niemeyer CM (2015) How I treat juvenile myelomonocytic leukemia. Blood 125: 1083-1090.

Locatelli F, Nollke P, Zecca M, Korthof E, Lanino E, Peters C, Pession A, Kabisch H, Uderzo C, Bonfim CS, Bader P, Dilloo D, Stary J, Fischer A, Revesz T, Fuhrer M, Hasle H, Trebo M, van den Heuvel-Eibrink MM, Fenu S, Strahm B, Giorgiani G, Bonora MR, Duffner U, Niemeyer CM (2005) Hematopoietic stem cell transplantation (HSCT) in children with juvenile myelomonocytic leukemia (JMML): results of the EWOG-MDS/ EBMT trial. Blood 105: 410-419.

Loh ML (2010) Childhood myelodysplastic syndrome: focus on the approach to diagnosis and treatment of juvenile myelomonocytic leukemia. Hematol Am Soc Hematol Educ Program 2010: 357-362.

Loh ML (2011) Recent advances in the pathogenesis and treatment of juvenile myelomonocytic leukaemia. Br J Haematol 152: 677-687.

Minuzzo M, Marchini S, Broggini M, Faircloth G, D’Incalci M, Mantovani R (2000) Interference of transcriptional activation by the antineoplastic drug ecteinascidin-743. Proc Natl Acad Sci USA 97: 6780-6784.

Monk BJ, Herzog TJ, Kaye SB, Krasner CN, Vermorken JB, Muggia FM, Pujade-Lauraine E, Lisyanskaya AS, Makhson AN, Rolski J, Gorbounova VA, Ghatage P, Bidzinski M, Shen K, Ngan HY, Vergote IB, Nam JH, Park YC, Lebedinsky CA, Poveda AM (2010) Trabectedin plus pegylated liposomal Doxorubicin in recurrent ovarian cancer. J Clin Oncol 28: 3107-3114.

Mulloy JC, Cancelas JA, Filippi MD, Kalfa TA, Guo F, Zheng Y (2010) Rho GTPases in hematopoiesis and hemopathies. Blood 115: 936-947.

Padron E, Painter JS, Kunigal S, Mailloux AW, McGraw K, McDaniel JM, Kim E, Bebbington C, Baer M, Yarranton G, Lancet J, Komrokji RS, Abdel-Wahab O, List AF, Epling-Burnette PK (2013) GM-CSF-dependent pSTAT5 sensitivity is a feature with therapeutic potential in chronic myelomonocytic leukemia. Blood 121: 5068-5077.

Patnaik MM, Parikh SA, Hanson CA, Tefferi A (2014) Chronic myelomonocytic leukaemia: a concise clinical and pathophysiological review. Br J Haematol 165: 273-286.

Patnaik MM, Tefferi A (2016) Chronic myelomonocytic leukemia: focus on clinical practice. Mayo Clin Proc 91: 259-272.

Perez-Ruixo JJ, Zannikos P, Hirankarn S, Stuyckens K, Ludwig EA, Soto-Matos A, Lopez-Lazaro L, Owen JS (2007) Population pharmacokinetic meta-analysis of trabectedin (ET-743, Yondelis) in cancer patients. Clin Pharmacokinet 46: 867-884.

Rucker FG, Sander S, Dohner K, Dohner H, Pollack JR, Bullinger L (2006) Molecular profiling reveals myeloid leukemia cell lines to be faithful model systems characterized by distinct genomic aberrations. Leukemia 20: $994-1001$. 
Sessa C, Cresta S, Noberasco C, Capri G, Gallerani E, De Braud F, Zucchetti M, D'Incalci M, Locatelli A, Marsoni S, Corradino I, Minoia C, Zintl P, Gianni L (2009a) Phase I clinical and pharmacokinetic study of trabectedin and cisplatin in solid tumours. Eur J Cancer 45: 2116-2122.

Sessa C, Perotti A, Noberasco C, De Braud F, Gallerani E, Cresta S, Zucchetti M, Vigano L, Locatelli A, Jimeno J, Feilchenfeldt JW, D’Incalci M, Capri G, Ielmini N, Gianni L (2009b) Phase I clinical and pharmacokinetic study of trabectedin and doxorubicin in advanced soft tissue sarcoma and breast cancer. Eur J Cancer 45: 1153-1161.

Soares DG, Poletto NP, Bonatto D, Salvador M, Schwartsmann G, Henriques JA (2005) Low cytotoxicity of ecteinascidin 743 in yeast lacking the major endonucleolytic enzymes of base and nucleotide excision repair pathways. Biochem Pharmacol 70: 59-69.

Steidl C, Lee T, Shah SP, Farinha P, Han G, Nayar T, Delaney A, Jones SJ, Iqbal J, Weisenburger DD, Bast MA, Rosenwald A, Muller-Hermelink HK, Rimsza LM, Campo E, Delabie J, Braziel RM, Cook JR, Tubbs RR, Jaffe ES, Lenz G, Connors JM, Staudt LM, Chan WC, Gascoyne RD (2010) Tumor-associated macrophages and survival in classic Hodgkin's lymphoma. N Engl J Med 362: 875-885.

Stieglitz E, Taylor-Weiner AN, Chang TY, Gelston LC, Wang YD, Mazor T, Esquivel E, Yu A, Seepo S, Olsen SR, Rosenberg M, Archambeault SL, Abusin G, Beckman K, Brown PA, Briones M, Carcamo B, Cooper T, Dahl GV, Emanuel PD, Fluchel MN, Goyal RK, Hayashi RJ, Hitzler J, Hugge C, Liu YL, Messinger YH, Mahoney Jr. DH, Monteleone P, Nemecek ER, Roehrs PA, Schore RJ, Stine KC, Takemoto CM, Toretsky JA, Costello JF, Olshen AB, Stewart C, Li Y, Ma J, Gerbing RB, Alonzo TA, Getz G, Gruber TA, Golub TR, Stegmaier K, Loh ML (2015) The genomic landscape of juvenile myelomonocytic leukemia. Nat Genet 47: 1326-1333.

Symeonidis A, van Biezen A, de Wreede L, Piciocchi A, Finke J, Beelen D, Bornhauser M, Cornelissen J, Volin L, Mufti G, Chalandon Y, Ganser A, Bruno B, Niederwieser D, Kobbe G, Schwerdtfeger R, de Witte T, Robin M, Kroger N (2015) Achievement of complete remission predicts outcome of allogeneic haematopoietic stem cell transplantation in patients with chronic myelomonocytic leukaemia. A study of the Chronic Malignancies Working Party of the European Group for Blood and Marrow Transplantation. Br J Haematol 171: 239-246.

Tavecchio M, Natoli C, Ubezio P, Erba E, D’Incalci M (2007) Dynamics of cell cycle phase perturbations by trabectedin (ET-743) in nucleotide excision repair (NER)-deficient and NER-proficient cells, unravelled by a novel mathematical simulation approach. Cell Prolif 40: 885-904.

Tavecchio M, Simone M, Erba E, Chiolo I, Liberi G, Foiani M, D’Incalci M, Damia G (2008) Role of homologous recombination in trabectedininduced DNA damage. Eur J Cancer 44: 609-618.

Troeger A, Williams DA (2013) Hematopoietic-specific Rho GTPases Rac2 and RhoH and human blood disorders. Exp Cell Res 319: 2375-2383.

Vardiman JW, Thiele J, Arber DA, Brunning RD, Borowitz MJ, Porwit A, Harris NL, Le Beau MM, Hellstrom-Lindberg E, Tefferi A, Bloomfield CD (2009) The 2008 revision of the World Health Organization (WHO) classification of myeloid neoplasms and acute leukemia: rationale and important changes. Blood 114: 937-951.

Yovine A, Riofrio M, Blay JY, Brain E, Alexandre J, Kahatt C, Taamma A, Jimeno J, Martin C, Salhi Y, Cvitkovic E, Misset JL (2004) Phase II study of ecteinascidin-743 in advanced pretreated soft tissue sarcoma patients. J Clin Oncol 22: 890-899.

Zewail-Foote M, Hurley LH (1999) Ecteinascidin 743: a minor groove alkylator that bends DNA toward the major groove. J Med Chem $\mathbf{4 2}$ 2493-2497.

This work is published under the standard license to publish agreement. After 12 months the work will become freely available and the license terms will switch to a Creative Commons AttributionNonCommercial-Share Alike 4.0 Unported License.

Supplementary Information accompanies this paper on British Journal of Cancer website (http://www.nature.com/bjc) 